\title{
Malaysia Corporate Credibility Index: An Assesment
}

\author{
A.M Dyg Affizzah \\ Faculty Economic and Business \\ Fathan Soetrisno \\ Universiti Kolej Teknologi Sarawak \\ Universiti Malaysia Sarawak \\ Y Irma Yazreen \\ Faculty Economic and Business \\ Universiti Malaysia Sarawak
}

Winnie Nirau

Universiti Kolej Teknologi Sarawak

Received: Aug. 8, 2019 Accepted: Sep. 17, 2019 Online published: Sep. 29, 2019

doi:10.5296/jpag.v9i3.15246

URL: https://doi.org/10.5296/jpag.v9i3.15246

\begin{abstract}
Corporate credibility has attracted interest from a wide range of academic disciplines. Malaysians tend to identify themselves by ethnic groups and not nationality. Cross-national marketing research that attempts to make comparisons and generalizations about Malaysian consumers, instead of Malay, Chinese or Indian sub-groups, is likely to be questionable. As corporate credibility index is crucial for every corporate, there is no benchmark or index in Malaysia context in determining levels of credibility of corporates. This provides an opportunity for this research to assess measurement invariance in cross-ethic perception difference between the westerner and Malaysian as well as developing a credibility index model called Malaysia organization credibility Index (MOCI) as an output of research. The Asian perception on corporate credibility may not be reliable and suitable if it is tested using the western-based scales, due to differences in ethnic culture, religious and personal values of the Asian consumers themselves. Nonetheless, one must determine whether such scales
\end{abstract}


exhibit cross-cultural equivalence before meaningful comparisons and generalizations can be made. Based on the SEM, the study finds out that both westerners and Asian seems to share the same perception on the honesty, trustworthiness and expertise. However, Asian perceived to see that customer and employees focus are the significant variables in perceiving the credibility of corporate organization and its reputation. Hence, increasingly, corporations in Asia will need to be cognizant of how they are perceived to achieve their strategic goals. This will involve understanding the impact of specific country reputations on firm reputation. Thus this study suggests the establishment of Malaysian Corporate Credibility Index that can be applied to Asian as a whole.

Keyword: corporate credibility, Asian

\section{Introduction}

Corporate credibility is the amount of trust and believe which companies need to design and deliver to their consumer to suit consumer needs and wants.(Newell, Goldsmith, and Lafferty (2000). Another term for corporate credibility as stated in a research done by Newell and Goldsmith (2001) is source credibility. Source credibility is commonly known as endorser credibility and advertiser credibility. This refers to celebrity or a spokesperson for a product or a company. These people or in other term called, endorser, generate changes in consumers' action toward the company (Lafferty and Goldsmith, 1999). Companies should not only rely only on endorsers but the image of the companies itself is an important factor to increase credibility and induce positive attitudes. Today, many companies have realized that the corporate image needs to be taken care of to capture consumers' attention. Corporate credibility sometimes has been ignored by many companies because they are too fond on using endorsers rather than associating themselves with positive environmental and social issues to enhance their reputation and to increase their sales volume.

Past studies show that there are many measurement scales used to indicate the level of corporate credibility. Such scales include company reputation, advertiser credibility, attitude toward the advertiser, merchant credibility, attitude toward the sponsor, company credibility, confidence or advertiser credibility and corporate credibility. There are a vast number of multi-item scales that can be used by international marketing researchers. Nonetheless, one must determine whether such scales exhibit cross-cultural equivalence before meaningful comparisons and generalizations can be made. Without evidence of measurement invariance, the cross-cultural findings of such studies are weak.

Many studies have assessed the cross-national measurement invariance of consumer behavior and marketing measures. Yet cross-cultural differences are likely to be significant, especially in multi-ethnic countries such as Malaysia.

Newell and Goldsmith (2001) developed a measurement scale to assess corporate credibility mainly based on the western perception. This however may not be applicable in Asian countries as some of the scales may not be valid. The measurement scale was developed based on the previous studies that ignore the context of Asian environment in the development of corporate credibility measurement index. 
Cultural differences are crucial in the process of portraying a good perception on a company, its advertisements, brands and others which can enhance the credibility of the companies. In Western countries such as the United States, freedom of choice is one of the factor that makes the companies can reach their target audience in many ways and credibility will be based on how consumer rate the particular company. Also, in the States, freedom of choice considered as an important social value whereas human interaction or relation approach has little or no impact on consumers. Asian countries such as India for example, freedom of choice cannot be considered as human value (Putti, 1991). This indicates that culture is an influential factor that most of the time plays a major role in consumer behavior. Putti (1991) definition of culture is 'the configuration of learned behaviour and results of behaviour whose component elements are shared and transmitted by members of a particular society.' The impact of culture differences on corporate credibility is the main focus of business as organization becomes more multi-cultural these days (Goodwin and Goodwin, 1999).

\section{Perceptions, Culture and Corporate Credibility in Asian Countries}

Perception as defined by Schiffman and Kanuk (2004), is the course of action by which an individual selects, organizes, and interprets stimuli into a meaningful and sound picture of the world. In a simple word, it is how one person or a group describe see the world. Kotler, Ang, Leong \& Tan (2003), indicate that perception can be different among individuals who are exposed to the same reality and it is not based on the physical stimuli but as well as the stimuli relation to the surrounding field and conditions within the individuals.

As for gaining credibility from a good perception, most company will be perceived as having high credibility or low credibility. If companies perceived as having a high level of credibility, it shows that they have delivered a satisfying services or a high quality products to their customers. Once the consumers have a perception of a certain company is capable of delivering a superior services or products they will tend to stay longer with the firm, creating certain level of loyalty towards the organisations. On the other hand, negative perception that creates low credibility towards he firm, will results in less demand from consumers and inability to retain customer.

Consumers have their own perceptions on how credible the firm is and one of the factors that strongly influenced their perception is culture. Kotler, Ang, Leong \& Tan (2003), found out that national culture or culture as a whole resulted in positive or negative word - of - mouth for service industries. For example, in Japan, consumers are prone to use the service of some Japanese small medium enterprise consultants based on referral from friends or families rather than using the service provided by the Westerners mainly, the American companies. Indonesian prefer to work with someone that they already know and fond of. To develop a business relationship in Indonesia with hope to portray a good perception, one should blend in with the crowd rather than communicating strictly on business issues. Malaysia on the other hand, they are easy going and informal and to capture their attentions, firm need to tackle them in a polite manner as Malaysians are rich with cultures from different races. Firms or marketers from outside the Asian countries should pay attention to these details because cultures are highly affecting the perceptions of the local firms since there are massive 


\section{Macrothink}

discrepancies between Asian and Western cultures altogether.

In addition, culture helps in shaping how one group of people behave and live their life in a proper manner. If one's culture is seen as disturbing, it will not only affect the community but the economic flows and business transactions. That provides an evident that culture do create a huge impact on perceptions. If the firms do not pay any respect or try to adapt to localize their business in the foreign country, it will be difficult for them to expand their business and gain trust from the locals. Decision making effort and style in Asian countries mostly differs from because it's less confrontation, deliberate compare to Western countries.

Understanding ethnicity is seen as crucial in understanding the functioning and viability of Malaysia's and Asian nations' multi-cultural society. Malaysians tend to identify themselves by ethnic groups and not nationality as in the case of Indonesians. Ethnic divisions in Malaysia are based on language use (Yoon,1998) in both formal and informal situations. The ethnic diversity in Malaysia is divisive, with individual ethnic groups having their own perceptions of social reality. This means that cross-national marketing research that attempts to make comparisons and generalizations about Malaysian consumers, instead of Malay, Chinese or Indian sub-groups, is likely to be questionable. This situation can also be seen throughout the various Asian nations.

\section{Theoretical Framework}

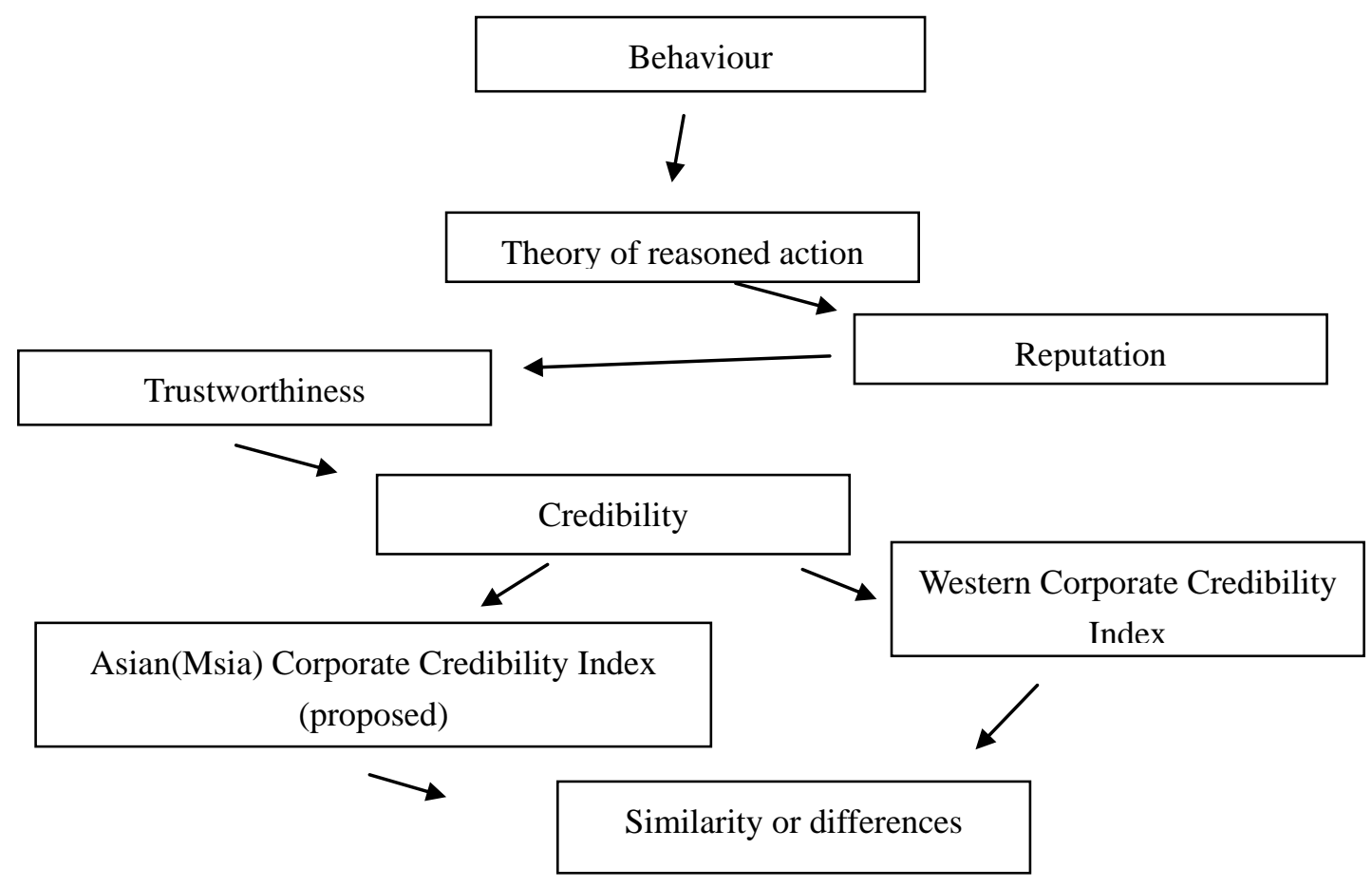

Based on the theoretical framework, it shows that behavior will induce the theory of reasoned action. This is because every consumer has different perceptions and when they consume the products of their desires, it will be based on their behavior toward the product itself. Brand 
names, styles, quality, perceptions on the product and many other are often the traits that influence the consumers in selecting their products or services. At this stage, the products or services will not be necessarily purchased. Although positive behavior can influence consumer to consume products or services it will never tell whether they will purchase the product or not. This model reacts based on behavior rather than the object itself. (Thompson, Haziris and Alekos, 1994).

Secondly, the Theory of Reasoned Action, also known as TRA is developed by Fishbein and Ajzen (1975) which refers to attitudes, behavior, and norms of individuals. It shows why an individual act they way they do. How individual behave is based on their beliefs.

Lastly, Malaysian based credibility index is prepared based on the existing model of corporate credibility index which was created by Newell and Goldsmith (2000). Based on the existing model, variables or factors which are similar can be used in the proposed model and few additional variables will be used along the way in order to suit it with the Asian market condition. Factors or scales such as cultures, perception differences between Asian and Westerners will be added in the model to make it appropriate for the Asian marketing environment.

\section{Methodology}

The study is based on both quantitative and qualitative analysis and uses a purposive sampling technique with established criteria for individual participant selection. Respondents are selected to provide a cross-section of the main ethnic groups in each country, with participants surveyed in firms of major cosmopolitan cities in Malaysia, such as Kuala Lumpur, Kuching, Sibu. There will be 250 respondents from all of these citties. Consumers in the 25 to 45 year old age group are identified as sampling targets, as these consumers are likely to be employed and have independent views of corporate credibility.

The data collection instrument is divided into two sections: Section one comprises items relating to individual values and religious belief, with scales sourced from established studies relating to personal values and religion. Respondents will be asked to respond to Likert scales (level of agreement on a scale of 1 to 7 with 7 being strongly agreed). Section two includes items relating to perception of individual towards corporate credibility. The scale is derived from Newell \& Goldsmith, (2001). The scale will utilize a 7 point Likert scale.

For the purpose of this study, Frequency Analysis, Mean, Exploratory Factor Analysis (EFA), ANOVA, MANOVA and Structural Equation Modeling (SEM) will be used to analyze the results. Structural Equation Modeling (SEM) is a statistical methodology that takes a confirmatory approach to the analysis of a structural theory bearing on some phenomenon (Byrne, 2001).

\section{Result}

The research consists of 200 respondent with several of ethnicity that represent the diveristy of Malaysian society such as Malay, Chinese, Indian, Iban and others. Majority race that involved in the survey is Malay respondent with a total of 107 respondents (53\%) and the 


\section{Macrothink}

second highest is Chinese with amount of 48 frespondents (24\%). Apart from that, the marital status is dominant by the married status which is 148 respondents (74\%) and followed by single status with 39 responden (20\%). Moreover, the study consists of 109 respondent $(55 \%)$ with Bumiputera status and the rest is non Bumputera. As for the education level, it shows that majority of the respondents are with Degree level, 106 respondent (52\%) and followed by Diploma/Matric/Foundation with 25\%.

The data is collected on the perceptions and different experiences based towards corporate credibility regardless their gender, age, race, marital status, nationality and education level. The result of mean distribution and standard deviation presented as below with initially 30 variables in total. The highest significant mean is referring to variable in Section $B$, question three (3) stating, 'a credible company is a company that provides a good quality of product to their customer,' with a mean of 4.2139 and the second highest is, 'a credible company is a company that value their customer,' with is 4.1898.. As for the Western Corprate Credibilty Statement in term of Asia perspectives indicates that the highest mean is, ' a credible company is a company that you can trust with mean of 5.5905 whilst followed by the expertise variable on the stament, ' a credible company has a great amount of experience'.

\section{Exploratory Factor Analysis (EFA)}

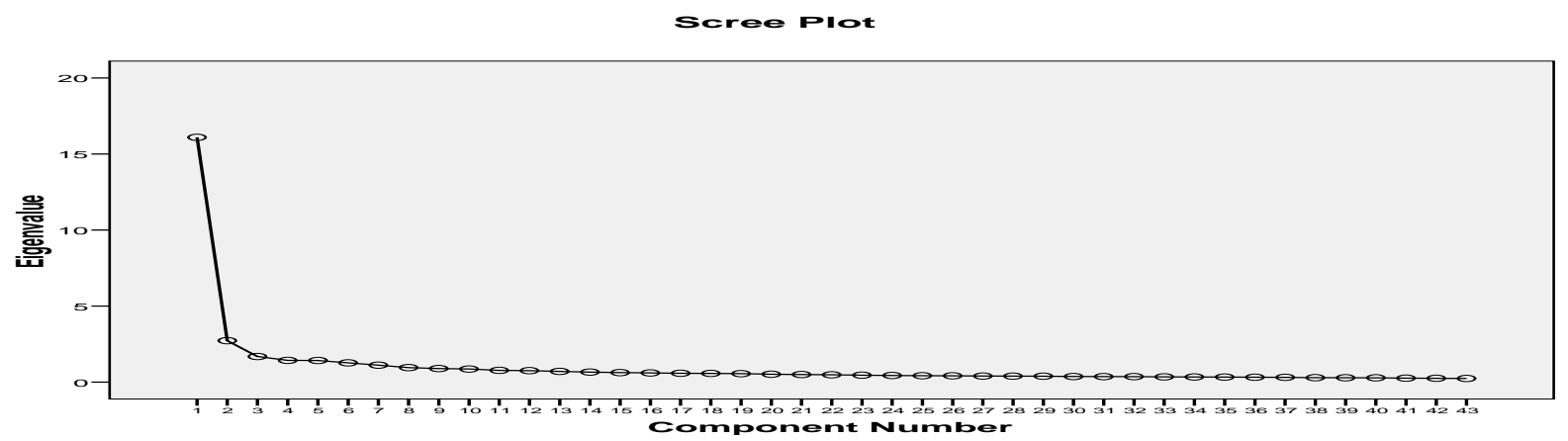

Based on Figure 1, only two (2) components from the seven (7) component matrix are accepted. A proper table will be shown for clearer picture of the findings.

\begin{tabular}{|l|l|l|}
\hline \multirow{2}{*}{ Variables } & Component \\
\cline { 2 - 3 } & $\begin{array}{l}\text { Customer } \\
\text { Oriented }\end{array}$ & $\begin{array}{l}\text { Expertise \& } \\
\text { Reliability }\end{array}$ \\
\hline $\begin{array}{l}\text { A credible company will always rectify any mistake that creates } \\
\text { customers dissatisfactions. }\end{array}$ & 0.638 & \\
\hline $\begin{array}{l}\text { A credible company will always regard its customer's feedback as } \\
\text { important. }\end{array}$ & 0.630 & \\
\hline A credible company is a company that can handle complaints well. & 0.610 & \\
\hline A credible company is able to ensure its sustained development. & & 0.619 \\
\hline
\end{tabular}




\begin{tabular}{|l|l|l|}
\hline A credible company provides regular training for its employees. & & 0.612 \\
\hline $\begin{array}{l}\text { A credible company is a company that has employees from various } \\
\text { educational background and expertise. }\end{array}$ & & 0.593 \\
\hline A credible company is a company that can be relied upon & & 0.564 \\
\hline $\begin{array}{l}\text { A credible company is a company that has been established for number } \\
\text { of years. }\end{array}$ & & 0.540 \\
\hline Eigenvalue & 16.095 & 2.723 \\
\hline \% of Variance & 37.431 & 6.334 \\
\hline Cumulative \% of Variance & 37.431 & 43.765 \\
\hline Reliability & 0.853 & 0.837 \\
\hline
\end{tabular}

\section{Confirmatory Factor Analysis (Structural Equation Model)}

Among the above criteria the Relative chi-square conforms the threshold value of a good fit and therefore the dataset has been successfully verifying to fit the model well (Bentler, 1990).

The structural equation model is composed of measurement model and structural model. In the measurement model the fit of the model or in other words how the theory fits the dataset is base on six criteria including the CFI, NFI, RMSEA and Relative chi-square. The following table shows the fit indices and also the recommended value against the current value.

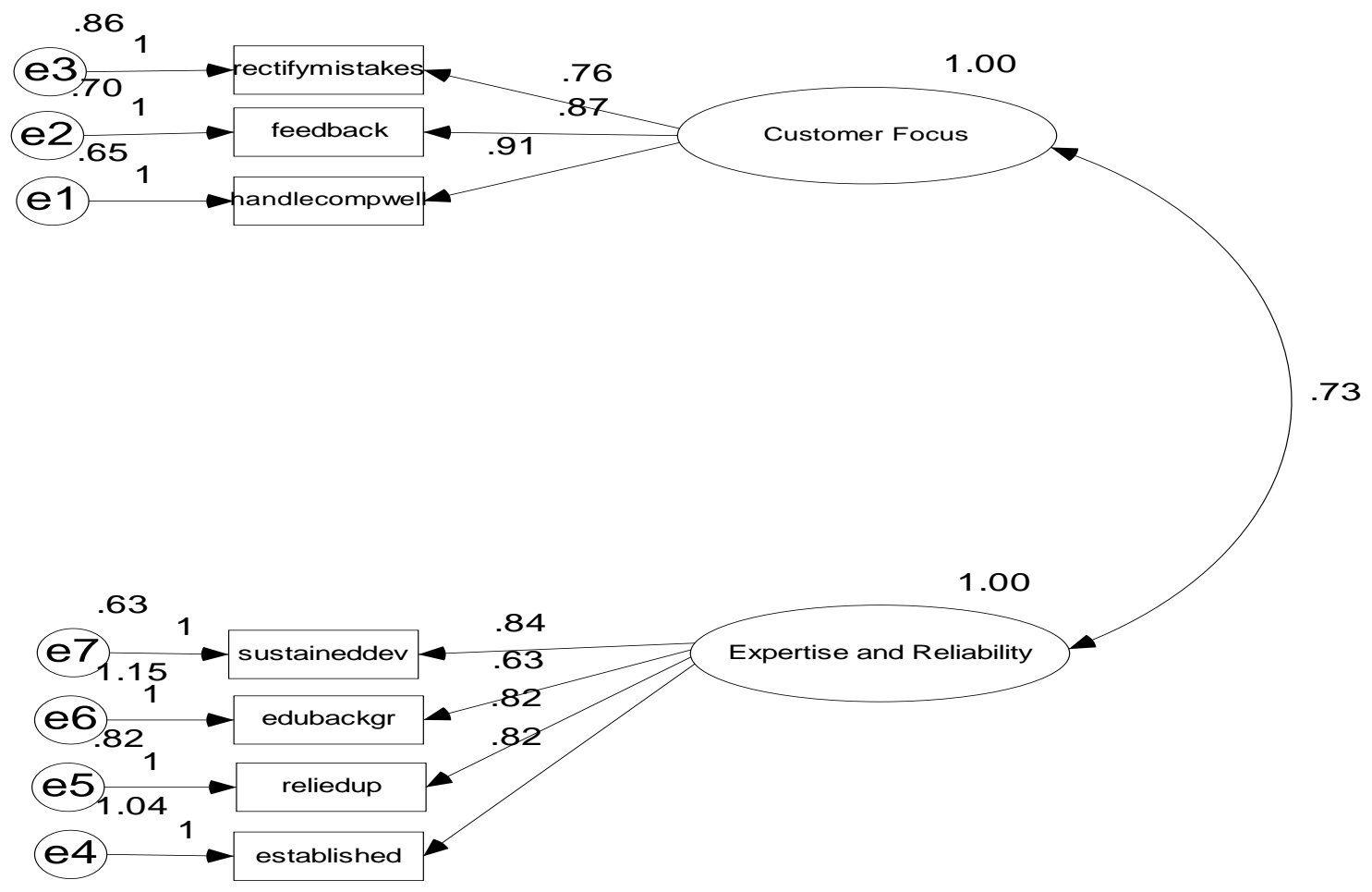




\section{Conclusion}

This paper aims to investigate the perception of various culture and ethnicity towards of corporate-brand credibility. Results reveal that the standardized regression coefficient of corporate-brand credibility using factors derived from Asian perspectives are much larger than that of perceived corporate-credibility using western scales origin, indicating that consumers with the different ethnicity and culture has different perception on corporate credibility's and reputation. Finally, the more specific is the variables used to describe corporate credibility in the perspectives of Asia, the higher the corporate credibility be. which is also consistent with prior research (e.g., Ericksen \& Sirgy, 1992; Sirgy \& Johar, 1999). Similarly, other research studies find that self-image congruence would influence consumers in terms of brand preference, loyalty, and satisfaction (e.g., Chebat, Sirgy, \& St-James, 2006; Sirgy, 1985). It is of perennial importance to ensure the validity of the instruments used to measure corporate credibility index, specifically between Western and Asian context to ensure the real scenario is understood well. . Ways of doing so include company-brand endorsement strategies and brand line campaigns. Companies need to conduct research on further variables-specific that can effectively communicate the desired elements to targeted consumers. In other words, the study suggests that there should be a new index in measuring corporate credibility in Malaysia, and Asia in general due to the diversity of ethnic and various culture that generate different perception and expectation on corporate's reputation and credibility.

\section{Fund}

The study is supported under 1496/2016: Fundamental Research Grant Scheme: Developing and Establishing Malaysian Credibility Index (MOCI), Ministry of Education Malaysia.

\section{References}

Byrne, A., Whitehead, M., Breen, S. (2001). The naked truth of celebrity endorsement. British Food Journal, 105(4-5), 288-296.

Chebat, J. C., Sirgy, M. J., \& St-James V. (2006). Up-scale image transfer from malls to stores: A self-image congruence explanation. Journal of Business Research, 59(12), 1288-1296.

Ericksen, M. K., \& Sirgy, M. J. (1992). Employed females' clothing preference, self-image congruence, and career anchorage. Journal of Applied Social Psychology, 22(5), 408-422.

Fishbein, M., \& Aizen, I. (1975). Belief, Attitude, Intention and Behaviour: An Introduction to Theory and Research. Reading, MA: Addison-Wesley, 1975.

Newell, S. J., Goldsmith, R. E., \& Lafferty, B. A. (2000). The impact of corporate credibility and celebrity credibility on consumer reaction to advertisements and brands. Journal of Advertising, XXIX(3).

Newell, S. J., Goldsmith, R. E., Lafferty, B. A. (2001). The Influence of Corporate Credibility on Consumer Attitudes and Purchase Intent. Corporate Reputation Review, 304-318. 


\section{Macrothink}

Journal of Public Administration and Governance ISSN 2161-7104 2019, Vol. 9, No. 3

Goodwin, J., \& Goodwin, D. (1999). Ethical judgements across cultures: A comparison between business students from Malaysia and New Zealand. Journal of Business Ethics, 267-281.

Kotler, L., Ang, \& Tan. (2003). Marketing Management: An Asian Perspective ( ${ }^{\text {rd }}$ Ed). Singapore: Prentice Hall.

Lafferty, B. A., \& Goldsmith, R. E. (1999). Corporate credibility's role in consumers' attitudes and purchase intentions when a high versus a low credibility endorser is used in the ad. Journal of Business Research, 44, 109-116.

Newell, S. J., \& Goldsmith, R. E. (1997). The development of a scale to measure perceived corporate credibility. Journal of Business Research, 235-247.

Putti, J. M. (Editor). (1991). Management: Asian Context. Singapore: McGraw-Hill Book Co.

Sirgy, M. J. (1985). Self-image/product image congruity and consumer decision-making. International Journal of Management, 2(4), 49-63.

Sirgy, M. J., \& Johar, J. S. (1999). Toward an integrated model of self-image congruence and functional con- gruence. European Advances in Consumer Research, 4, 252-256.

Schiffman, L. K. (2004). Consumer Behavior,(7th ed.). New Jersey: Prentice Hall International.

Thompson. et al. (1994) Strategy: core concepts, Analytical tools and reading. 2nd Ed. McGraw-Hill: Boston.

Yoon, K., Kim, C. H., \& Kim, M. S. (1998). A Cross-Cultral Comparison of the Effects of Source Credibilkity on Attitudes and Behavioral Intentions. Mass Communication \& Society, 1(3/4), 153-173.

\section{Copyright Disclaimer}

Copyright for this article is retained by the author(s), with first publication rights granted to the journal.

This is an open-access article distributed under the terms and conditions of the Creative Commons Attribution license (http://creativecommons.org/licenses/by/4.0/). 